\title{
Weak and Strong Convergence Theorems for Asymptotically Strict Pseudocontractive Mappings in the Intermediate Sense
}

\author{
Jing Zhao ${ }^{1,2}$ and Songnian $\mathrm{He}^{1,2}$ \\ ${ }^{1}$ College of Science, Civil Aviation University of China, Tianjin 300300, China \\ 2 Tianjin Key Laboratory For Advanced Signal Processing, Civil Aviation University of China, \\ Tianjin 300300, China
}

Correspondence should be addressed to Jing Zhao, zhaojing200103@163.com

Received 23 June 2010; Accepted 19 October 2010

Academic Editor: W. A. Kirk

Copyright (C) 2010 J. Zhao and S. He. This is an open access article distributed under the Creative Commons Attribution License, which permits unrestricted use, distribution, and reproduction in any medium, provided the original work is properly cited.

\begin{abstract}
We study the convergence of Ishikawa iteration process for the class of asymptotically $\kappa$-strict pseudocontractive mappings in the intermediate sense which is not necessarily Lipschitzian. Weak convergence theorem is established. We also obtain a strong convergence theorem by using hybrid projection for this iteration process. Our results improve and extend the corresponding results announced by many others.
\end{abstract}

\section{Introduction and Preliminaries}

Throughout this paper, we always assume that $H$ is a real Hilbert space with inner product $\langle\cdot, \cdot\rangle$ and norm $\|\cdot\| . \rightarrow$ and $\rightarrow$ denote weak and strong convergence, respectively. $\omega_{w}\left(x_{n}\right)$ denotes the weak $\omega$-limit set of $\left\{x_{n}\right\}$, that is, $\omega_{w}\left(x_{n}\right)=\left\{x \in H: \exists x_{n_{j}} \rightarrow x\right\}$. Let $C$ be a nonempty closed convex subset of $H$. It is well known that for every point $x \in H$, there exists a unique nearest point in $C$, denoted by $P_{C} x$, such that

$$
\left\|x-P_{C} x\right\| \leq\|x-y\|
$$

for all $y \in C$. $P_{C}$ is called the metric projection of $H$ onto $C$. $P_{C}$ is a nonexpansive mapping of $H$ onto $C$ and satisfies

$$
\left\langle x-y, P_{C} x-P_{C} y\right\rangle \geq\left\|P_{C} x-P_{C} y\right\|^{2}, \quad \forall x, y \in H .
$$


Let $T: C \rightarrow C$ be a mapping. In this paper, we denote the fixed point set of $T$ by $F(T)$. Recall that $T$ is said to be uniformly $L$-Lipschitzian if there exists a constant $L>0$, such that

$$
\left\|T^{n} x-T^{n} y\right\| \leq L\|x-y\|, \quad \forall x, y \in C, \forall n \geq 1 .
$$

$T$ is said to be nonexpansive if

$$
\|T x-T y\| \leq\|x-y\|, \quad \forall x, y \in C \text {. }
$$

$T$ is said to be asymptotically nonexpansive if there exists a sequence $\left\{k_{n}\right\}$ in $[1, \infty)$ with $\lim _{n \rightarrow \infty} k_{n}=1$, such that

$$
\left\|T^{n} x-T^{n} y\right\| \leq k_{n}\|x-y\|, \quad \forall x, y \in C, \forall n \geq 1 .
$$

The class of asymptotically nonexpansive mappings was introduced by Goebel and Kirk [1] as a generalization of the class of nonexpansive mappings. $T$ is said to be asymptotically nonexpansive in the intermediate sense if it is continuous and the following inequality holds:

$$
\limsup _{n \rightarrow \infty} \sup _{x, y \in C}\left(\left\|T^{n} x-T^{n} y\right\|-\|x-y\|\right) \leq 0 .
$$

Observe that if we define

$$
\tau_{n}=\max \left\{0, \sup _{x, y \in C}\left(\left\|T^{n} x-T^{n} y\right\|-\|x-y\|\right)\right\}
$$

then $\tau_{n} \rightarrow 0$ as $n \rightarrow \infty$. It follows that (1.6) is reduced to

$$
\left\|T^{n} x-T^{n} y\right\| \leq\|x-y\|+\tau_{n}, \quad \forall x, y \in C, \forall n \geq 1 .
$$

The class of mappings which are asymptotically nonexpansive in the intermediate sense was introduced by Bruck et al. [2]. It is known [3] that if $C$ is a nonempty closed convex bounded subset of a uniformly convex Banach space $E$ and $T$ is asymptotically nonexpansive in the intermediate sense, then $T$ has a fixed point. It is worth mentioning that the class of mappings which are asymptotically nonexpansive in the intermediate sense contains properly the class of asymptotically nonexpansive mappings.

Recall that $T$ is said to be a $\kappa$-strict pseudocontraction if there exists a constant $\mathcal{K} \in$ $[0,1)$, such that

$$
\|T x-T y\|^{2} \leq\|x-y\|^{2}+\kappa\|(I-T) x-(I-T) y\|^{2}, \quad \forall x, y \in C .
$$


$T$ is said to be an asymptotically $\kappa$-strict pseudocontraction with sequence $\left\{\gamma_{n}\right\}$ if there exist a constant $\kappa \in[0,1)$ and a sequence $\left\{\gamma_{n}\right\} \subset[0, \infty)$ with $\gamma_{n} \rightarrow 0$ as $n \rightarrow \infty$, such that

$$
\left\|T^{n} x-T^{n} y\right\|^{2} \leq\left(1+\gamma_{n}\right)\|x-y\|^{2}+\kappa\left\|\left(I-T^{n}\right) x-\left(I-T^{n}\right) y\right\|^{2}, \quad \forall x, y \in C, n \geq 1 .
$$

The class of asymptotically $\kappa$-strict pseudocontractions was introduced by Qihou [4] in 1996 (see also [5]). Kim and Xu [6] studied weak and strong convergence theorems for this class of mappings. It is important to note that every asymptotically $\mathcal{\kappa}$-strict pseudocontractive mapping with sequence $\left\{\gamma_{n}\right\}$ is a uniformly $L$-Lipschitzian mapping with $L=\sup \{(\kappa+$ $\left.\left.\sqrt{1+(1-\kappa) \gamma_{n}}\right) /(1+\kappa): n \in N\right\}$.

Recently, Sahu et al. [7] introduced a class of new mappings: asymptotically $\kappa$ strict pseudocontractive mappings in the intermediate sense. Recall that $T$ is said to be an asymptotically $\kappa$-strict pseudocontraction in the intermediate sense with sequence $\left\{\gamma_{n}\right\}$ if there exist a constant $\mathcal{K} \in[0,1)$ and a sequence $\left\{\gamma_{n}\right\} \subset[0, \infty)$ with $\gamma_{n} \rightarrow 0$ as $n \rightarrow \infty$, such that

$$
\limsup _{n \rightarrow \infty} \sup _{x, y \in C}\left(\left\|T^{n} x-T^{n} y\right\|^{2}-\left(1+\gamma_{n}\right)\|x-y\|^{2}-\kappa\left\|\left(I-T^{n}\right) x-\left(I-T^{n}\right) y\right\|^{2}\right) \leq 0 .
$$

Throughout this paper, we assume that

$$
c_{n}=\max \left\{0, \sup _{x, y \in C}\left(\left\|T^{n} x-T^{n} y\right\|^{2}-\left(1+\gamma_{n}\right)\|x-y\|^{2}-\kappa\left\|\left(I-T^{n}\right) x-\left(I-T^{n}\right) y\right\|^{2}\right)\right\} .
$$

It follows that $c_{n} \rightarrow 0$ as $n \rightarrow \infty$ and (1.11) is reduced to the relation

$$
\left\|T^{n} x-T^{n} y\right\|^{2} \leq\left(1+\gamma_{n}\right)\|x-y\|^{2}+\kappa\left\|\left(I-T^{n}\right) x-\left(I-T^{n}\right) y\right\|^{2}+c_{n}, \quad \forall x, y \in C .
$$

They obtained a weak convergence theorem of modified Mann iterative processes for the class of mappings which is not necessarily Lipschitzian. Moreover, a strong convergence theorem was also established in a real Hilbert space by hybrid projection methods; see [7] for more details.

In this paper, we consider the problem of convergence of Ishikawa iterative processes for the class of asymptotically $\kappa$-strict pseudocontractive mappings in the intermediate sense.

In order to prove our main results, we also need the following lemmas.

Lemma 1.1 (see $[8,9])$. Let $\left\{\delta_{n}\right\},\left\{\beta_{n}\right\}$, and $\left\{\gamma_{n}\right\}$ be three sequences of nonnegative numbers satisfying the recursive inequality

$$
\delta_{n+1} \leq \beta_{n} \delta_{n}+\gamma_{n}, \quad \forall n \geq 1 .
$$

If $\beta_{n} \geq 1, \sum_{n=1}^{\infty}\left(\beta_{n}-1\right)<\infty$ and $\sum_{n=1}^{\infty} \gamma_{n}<\infty$, then $\lim _{n \rightarrow \infty} \delta_{n}$ exists. 
Lemma 1.2 (see [10]). Let $\left\{x_{n}\right\}$ be a bounded sequence in a reflexive Banach space X. If $\omega_{w}\left(x_{n}\right)=$ $\{x\}$, then $x_{n} \rightarrow x$.

Lemma 1.3 (see [11]). Let $C$ be a nonempty closed convex subset of a real Hilbert space $H$. Given $x \in H$ and $z \in C$, then $z=P_{C} x$ if and only if $\langle x-z, y-z\rangle \leq 0$, for all $y \in C$.

Lemma 1.4 (see [11]). For a real Hilbert space $H$, the following identities hold:

(i) $\|x-y\|^{2}=\|x\|^{2}-\|y\|^{2}-2\langle x-y, y\rangle$, for all $x, y \in H$,

(ii) $\|t x+(1-t) y\|^{2}=t\|x\|^{2}+(1-t)\|y\|^{2}-t(1-t)\|x-y\|^{2}$, for all $t \in[0,1]$, for all $x, y \in H$;

(iii) (Opial condition) If $\left\{x_{n}\right\}$ is a sequence in $H$ weakly convergent to $z$, then

$$
\limsup _{n \rightarrow \infty}\left\|x_{n}-y\right\|^{2}=\limsup _{n \rightarrow \infty}\left\|x_{n}-z\right\|^{2}+\|z-y\|^{2}, \quad \forall y \in H .
$$

Lemma 1.5 (see [7]). Let $C$ be a nonempty subset of a Hilbert space $H$ and $T: C \rightarrow C$ an asymptotically $\mathcal{\kappa}$-strict pseudocontractive mapping in the intermediate sense with sequence $\left\{\gamma_{n}\right\}$. Then

$$
\begin{array}{r}
\left\|T^{n} x-T^{n} y\right\| \leq \frac{1}{1-\kappa}\left(\kappa\|x-y\|+\sqrt{\left(1+(1-\kappa) \gamma_{n}\right)\|x-y\|^{2}+(1-\kappa) c_{n}}\right) \\
\forall x, y \in C, \forall n \in \mathbb{N} .
\end{array}
$$

Lemma 1.6. Let $C$ be a nonempty subset of a Hilbert space $H$ and $T: C \rightarrow C$ an asymptotically $\kappa$-strict pseudocontractive mapping in the intermediate sense with sequence $\left\{\gamma_{n}\right\}$. Let $n \in \mathbb{N}$. If $\gamma_{n}<1$, then

$$
\left\|T^{n} x-T^{n} y\right\| \leq \frac{1}{1-\kappa}\left((\kappa+\sqrt{2-\kappa})\|x-y\|+\sqrt{c_{n}}\right), \quad \forall x, y \in C
$$

Proof. If $\gamma_{n}<1$, for $x, y \in C$, we obtain from Lemma 1.5 that

$$
\begin{aligned}
\left\|T^{n} x-T^{n} y\right\| & \leq \frac{1}{1-\kappa}\left(\kappa\|x-y\|+\sqrt{\left(1+(1-\kappa) \gamma_{n}\right)\|x-y\|^{2}+(1-\kappa) c_{n}}\right) \\
& \leq \frac{1}{1-\kappa}\left(\kappa\|x-y\|+\sqrt{(2-\kappa)\|x-y\|^{2}+c_{n}}\right) \\
& \leq \frac{1}{1-\kappa}\left\{\kappa\|x-y\|+\sqrt{\left(\sqrt{2-\kappa}\|x-y\|+\sqrt{c_{n}}\right)^{2}}\right\} \\
& =\frac{1}{1-\kappa}\left((\kappa+\sqrt{2-\kappa})\|x-y\|+\sqrt{c_{n}}\right) .
\end{aligned}
$$

Lemma 1.7 (see [7]). Let $C$ be a nonempty subset of a Hilbert space $H$ and $T: C \rightarrow C$ a uniformly continuous asymptotically $\boldsymbol{\kappa}$-strict pseudocontractive mapping in the intermediate sense with sequence $\left\{\gamma_{n}\right\}$. Let $\left\{x_{n}\right\}$ be a sequence in $C$ such that $\left\|x_{n}-x_{n+1}\right\| \rightarrow 0$ and $\left\|x_{n}-T^{n} x_{n}\right\| \rightarrow 0$ as $n \rightarrow \infty$, then $\left\|x_{n}-T x_{n}\right\| \rightarrow 0$ as $n \rightarrow \infty$. 
Lemma 1.8 (see [7, Proposition 3.1]). Let $C$ be a nonempty closed convex subset of a Hilbert space $H$ and $T: C \rightarrow C$ a continuous asymptotically $\kappa$-strict pseudocontractive mapping in the intermediate sense. Then $I-T$ is demiclosed at zero in the sense that if $\left\{x_{n}\right\}$ is a sequence in $C$ such that $x_{n} \rightarrow x \in C$ and $\lim \sup _{m \rightarrow \infty} \lim \sup _{n \rightarrow \infty}\left\|x_{n}-T^{m} x_{n}\right\|=0$, then $(I-T) x=0$.

Lemma 1.9 (see [7]). Let $C$ be a nonempty closed convex subset of a Hilbert space $H$ and $T: C \rightarrow C$ a continuous asymptotically $\kappa$-strict pseudocontractive mapping in the intermediate sense. Then $F(T)$ is closed and convex.

\section{Main Results}

Theorem 2.1. Let $C$ be a nonempty closed convex subset of a Hilbert space $H$ and $T: C \rightarrow C$ a uniformly continuous asymptotically $\kappa$-strict pseudocontractive mapping in the intermediate sense with sequence $\left\{\gamma_{n}\right\}$ such that $F(T) \neq \emptyset$. Let $\left\{x_{n}\right\}_{n=1}^{\infty}$ be a sequence in $C$ generated by the following Ishikawa iterative process:

$$
\begin{gathered}
x_{1} \in C, \\
y_{n}=\beta_{n} T^{n} x_{n}+\left(1-\beta_{n}\right) x_{n}, \\
x_{n+1}=\alpha_{n} T^{n} y_{n}+\left(1-\alpha_{n}\right) x_{n}, \quad \forall n \geq 1,
\end{gathered}
$$

where $\left\{\alpha_{n}\right\}$ and $\left\{\beta_{n}\right\}$ are sequences in $(0,1)$. Assume that the following restrictions are satisfied:

(i) $\sum_{n=1}^{\infty} \alpha_{n} c_{n}<\infty$ and $\sum_{n=1}^{\infty}\left(\left(1+\gamma_{n}\right)^{2}-1\right)<\infty$,

(ii) $0<a \leq \alpha_{n} \leq \beta_{n} \leq b$ for some $a>0$ and $b \in\left(0,\left(-(1-\kappa)^{2}+\right.\right.$ $\left.\left.\sqrt{(1-\kappa)^{4}+2(\kappa+\sqrt{2-\kappa})^{2}(1-\kappa)^{2}}\right) / 2(\kappa+\sqrt{2-\kappa})^{2}\right)$.

Then the sequence $\left\{x_{n}\right\}$ given by (2.1) converges weakly to an element of $F(T)$.

Proof. Let $p \in F(T)$. From (1.13) and Lemma 1.4, we see that

$$
\begin{aligned}
\left\|y_{n}-p\right\|^{2}= & \left\|\beta_{n}\left(T^{n} x_{n}-p\right)+\left(1-\beta_{n}\right)\left(x_{n}-p\right)\right\|^{2} \\
= & \beta_{n}\left\|T^{n} x_{n}-p\right\|^{2}+\left(1-\beta_{n}\right)\left\|x_{n}-p\right\|^{2}-\beta_{n}\left(1-\beta_{n}\right)\left\|x_{n}-T^{n} x_{n}\right\|^{2} \\
\leq & \beta_{n}\left(\left(1+\gamma_{n}\right)\left\|x_{n}-p\right\|^{2}+\kappa\left\|x_{n}-T^{n} x_{n}\right\|^{2}+c_{n}\right) \\
& +\left(1-\beta_{n}\right)\left\|x_{n}-p\right\|^{2}-\beta_{n}\left(1-\beta_{n}\right)\left\|x_{n}-T^{n} x_{n}\right\|^{2} \\
\leq & \left(1+\gamma_{n}\right)\left\|x_{n}-p\right\|^{2}-\beta_{n}\left(1-\beta_{n}-\kappa\right)\left\|x_{n}-T^{n} x_{n}\right\|^{2}+\beta_{n} c_{n} .
\end{aligned}
$$


Without loss of generality, we may assume that $\gamma_{n}<1$ for all $n \in \mathbb{N}$. Since

$$
\left\|x_{n}-y_{n}\right\|^{2}=\left\|x_{n}-\beta_{n} T^{n} x_{n}-\left(1-\beta_{n}\right) x_{n}\right\|^{2}=\beta_{n}^{2}\left\|x_{n}-T^{n} x_{n}\right\|^{2},
$$

it follows from Lemma 1.6 that

$$
\begin{aligned}
\left\|y_{n}-T^{n} y_{n}\right\|^{2}= & \left\|\beta_{n}\left(T^{n} x_{n}-T^{n} y_{n}\right)+\left(1-\beta_{n}\right)\left(x_{n}-T^{n} y_{n}\right)\right\|^{2} \\
= & \beta_{n}\left\|T^{n} x_{n}-T^{n} y_{n}\right\|^{2}+\left(1-\beta_{n}\right)\left\|x_{n}-T^{n} y_{n}\right\|^{2}-\beta_{n}\left(1-\beta_{n}\right)\left\|x_{n}-T^{n} x_{n}\right\|^{2} \\
\leq & \frac{\beta_{n}}{(1-\kappa)^{2}}\left((\kappa+\sqrt{2-\kappa})\left\|x_{n}-y_{n}\right\|+\sqrt{c_{n}}\right)^{2} \\
& +\left(1-\beta_{n}\right)\left\|x_{n}-T^{n} y_{n}\right\|^{2}-\beta_{n}\left(1-\beta_{n}\right)\left\|x_{n}-T^{n} x_{n}\right\|^{2} \\
\leq & 2 \beta_{n}^{3}\left(\frac{\kappa+\sqrt{2-\kappa}}{1-\kappa}\right)^{2}\left\|x_{n}-T^{n} x_{n}\right\|^{2}+\frac{2 \beta_{n} c_{n}}{(1-\kappa)^{2}} \\
& +\left(1-\beta_{n}\right)\left\|x_{n}-T^{n} y_{n}\right\|^{2}-\beta_{n}\left(1-\beta_{n}\right)\left\|x_{n}-T^{n} x_{n}\right\|^{2} .
\end{aligned}
$$

By (2.2) and (2.4), we obtain that

$$
\begin{aligned}
&\left\|T^{n} y_{n}-p\right\|^{2} \\
& \leq\left(1+\gamma_{n}\right)\left\|y_{n}-p\right\|^{2}+\kappa\left\|y_{n}-T^{n} y_{n}\right\|^{2}+c_{n} \\
& \leq\left(1+\gamma_{n}\right)^{2}\left\|x_{n}-p\right\|^{2}-\beta_{n}\left(1+\gamma_{n}\right)\left(1-\beta_{n}-\kappa\right)\left\|x_{n}-T^{n} x_{n}\right\|^{2} \\
&+\beta_{n}\left(1+\gamma_{n}\right) c_{n}+2 \kappa \beta_{n}^{3}\left(\frac{\kappa+\sqrt{2-\kappa}}{1-\kappa}\right)^{2}\left\|x_{n}-T^{n} x_{n}\right\|^{2}+\frac{2 \kappa \beta_{n} c_{n}}{(1-\kappa)^{2}} \\
&+\kappa\left(1-\beta_{n}\right)\left\|x_{n}-T^{n} y_{n}\right\|^{2}-\kappa \beta_{n}\left(1-\beta_{n}\right)\left\|x_{n}-T^{n} x_{n}\right\|^{2}+c_{n} \\
&=\left(1+\gamma_{n}\right)^{2}\left\|x_{n}-p\right\|^{2}-\beta_{n}\left[\left(1+\gamma_{n}\right)\left(1-\beta_{n}-\kappa\right)-2 \kappa \beta_{n}^{2}\left(\frac{\kappa+\sqrt{2-\kappa}}{1-\kappa}\right)^{2}+\kappa\left(1-\beta_{n}\right)\right] \\
& \times\left\|x_{n}-T^{n} x_{n}\right\|^{2}+\kappa\left(1-\beta_{n}\right)\left\|x_{n}-T^{n} y_{n}\right\|^{2}+c_{n} M_{1},
\end{aligned}
$$


Fixed Point Theory and Applications

where $M_{1}=\sup _{n \geq 1}\left\{\beta_{n}\left(1+\gamma_{n}\right)+2 \kappa \beta_{n} /(1-\kappa)^{2}+1\right\}$. It follows from (2.5) and $\alpha_{n} \leq \beta_{n}$ that

$$
\begin{aligned}
\| x_{n+1}- & p \|^{2} \\
= & \left\|\alpha_{n}\left(T^{n} y_{n}-p\right)+\left(1-\alpha_{n}\right)\left(x_{n}-p\right)\right\|^{2} \\
= & \alpha_{n}\left\|T^{n} y_{n}-p\right\|^{2}+\left(1-\alpha_{n}\right)\left\|x_{n}-p\right\|^{2}-\alpha_{n}\left(1-\alpha_{n}\right)\left\|T^{n} y_{n}-x_{n}\right\|^{2} \\
\leq & \alpha_{n}\left(1+\gamma_{n}\right)^{2}\left\|x_{n}-p\right\|^{2}-\alpha_{n} \beta_{n}\left[\left(1+\gamma_{n}\right)\left(1-\beta_{n}-\kappa\right)-2 \kappa \beta_{n}^{2}\left(\frac{\kappa+\sqrt{2-\kappa}}{1-\kappa}\right)^{2}+\kappa\left(1-\beta_{n}\right)\right] \\
& \times\left\|x_{n}-T^{n} x_{n}\right\|^{2}+\alpha_{n} \kappa\left(1-\beta_{n}\right)\left\|x_{n}-T^{n} y_{n}\right\|^{2} \\
& +\alpha_{n} c_{n} M_{1}+\left(1-\alpha_{n}\right)\left\|x_{n}-p\right\|^{2}-\alpha_{n}\left(1-\alpha_{n}\right)\left\|T^{n} y_{n}-x_{n}\right\|^{2} \\
\leq & \left(1+\gamma_{n}\right)^{2}\left\|x_{n}-p\right\|^{2}-\alpha_{n} \beta_{n}\left[\left(1+\gamma_{n}\right)\left(1-\beta_{n}\right)-\kappa \gamma_{n}-2 \kappa \beta_{n}^{2}\left(\frac{\kappa+\sqrt{2-\kappa}}{1-\kappa}\right)^{2}-\kappa \beta_{n}\right] \\
& \times\left\|x_{n}-T^{n} x_{n}\right\|^{2}-\alpha_{n}\left(1-\alpha_{n}-\kappa\left(1-\beta_{n}\right)\right)\left\|x_{n}-T^{n} y_{n}\right\|^{2}+\alpha_{n} c_{n} M_{1} \\
\leq & \left(1+\gamma_{n}\right)^{2}\left\|x_{n}-p\right\|^{2}-\alpha_{n} \beta_{n}\left[\left(1+\gamma_{n}\right)\left(1-\beta_{n}\right)-\kappa \gamma_{n}-2 \kappa \beta_{n}^{2}\left(\frac{\kappa+\sqrt{2-\kappa}}{1-\kappa}\right)^{2}-\kappa \beta_{n}\right] \\
& \times\left\|x_{n}-T^{n} x_{n}\right\|^{2}+\alpha_{n} c_{n} M_{1} .
\end{aligned}
$$

From the condition (ii) and $\gamma_{n} \rightarrow 0$, we see that there exists $n_{0}$ such that

$$
\begin{aligned}
\left(1+\gamma_{n}\right) & \left(1-\beta_{n}\right)-\kappa \gamma_{n}-2 \kappa \beta_{n}^{2}\left(\frac{\kappa+\sqrt{2-\kappa}}{1-\kappa}\right)^{2}-\kappa \beta_{n} \\
& \geq 1-\beta_{n}-\kappa \gamma_{n}-2 \beta_{n}^{2}\left(\frac{\kappa+\sqrt{2-\kappa}}{1-\kappa}\right)^{2}-\kappa \beta_{n} \\
& \geq 1-2 \beta_{n}-\kappa \gamma_{n}-2 \beta_{n}^{2}\left(\frac{\kappa+\sqrt{2-\kappa}}{1-\kappa}\right)^{2} \\
& \geq 1-2 b-2 b^{2}\left(\frac{\kappa+\sqrt{2-\kappa}}{1-\kappa}\right)^{2}-\kappa \gamma_{n} \\
& \geq \frac{1}{2}\left(1-2 b-2 b^{2}\left(\frac{\kappa+\sqrt{2-\kappa}}{1-\kappa}\right)^{2}\right)>0, \quad \forall n \geq n_{0} .
\end{aligned}
$$


By (2.6), we have

$$
\left\|x_{n+1}-p\right\|^{2} \leq\left(1+\gamma_{n}\right)^{2}\left\|x_{n}-p\right\|^{2}+\alpha_{n} c_{n} M_{1}, \quad \forall n \geq n_{0}
$$

In view of Lemma 1.1 and the condition (i), we obtain that $\lim _{n \rightarrow \infty}\left\|x_{n}-p\right\|$ exists. For any $n \geq n_{0}$, it is easy to see from (2.6) and (2.7) that

$$
\begin{aligned}
& \frac{a^{2}}{2}\left(1-2 b-2 b^{2}\left(\frac{\kappa+\sqrt{2-\kappa}}{1-\kappa}\right)^{2}\right)\left\|x_{n}-T^{n} x_{n}\right\|^{2} \\
& \leq\left(1+\gamma_{n}\right)^{2}\left\|x_{n}-p\right\|^{2}-\left\|x_{n+1}-p\right\|^{2}+\alpha_{n} c_{n} M_{1}
\end{aligned}
$$

which implies that

$$
\lim _{n \rightarrow \infty}\left\|x_{n}-T^{n} x_{n}\right\|=0
$$

Note that

$$
\begin{aligned}
\left\|x_{n+1}-x_{n}\right\| & =\alpha_{n}\left\|T^{n} y_{n}-x_{n}\right\| \\
& \leq \alpha_{n}\left\|T^{n} y_{n}-T^{n} x_{n}\right\|+\alpha_{n}\left\|T^{n} x_{n}-x_{n}\right\| \\
& \leq \frac{\alpha_{n}}{1-\kappa}\left((\kappa+\sqrt{2-\kappa})\left\|x_{n}-y_{n}\right\|+\sqrt{c_{n}}\right)+\alpha_{n}\left\|T^{n} x_{n}-x_{n}\right\| \\
& =\frac{\alpha_{n} \beta_{n}}{1-\kappa}(\kappa+\sqrt{2-\kappa})\left\|x_{n}-T^{n} x_{n}\right\|+\frac{\alpha_{n} \sqrt{c_{n}}}{1-\kappa}+\alpha_{n}\left\|T^{n} x_{n}-x_{n}\right\| .
\end{aligned}
$$

From (2.10), we have

$$
\lim _{n \rightarrow \infty}\left\|x_{n+1}-x_{n}\right\|=0
$$

Since $T$ is uniformly continuous, we obtain from (2.10), (2.12) and Lemma 1.7 that

$$
\lim _{n \rightarrow \infty}\left\|x_{n}-T x_{n}\right\|=0
$$

By the boundedness of $\left\{x_{n}\right\}$, there exist a subsequence $\left\{x_{n_{k}}\right\}$ of $\left\{x_{n}\right\}$ such that $x_{n_{k}} \rightarrow x$. Observe that $T$ is uniformly continuous and $\left\|x_{n}-T x_{n}\right\| \rightarrow 0$ as $n \rightarrow \infty$, for any $m \in \mathbb{N}$ we have $\left\|x_{n}-T^{m} x_{n}\right\| \rightarrow 0$ as $n \rightarrow \infty$. From Lemma 1.8, we see that $x \in F(T)$.

To complete the proof, it suffices to show that $\omega_{w}\left(\left\{x_{n}\right\}\right)$ consists of exactly one point, namely, $x$. Suppose there exists another subsequence $\left\{x_{n_{j}}\right\}$ of $\left\{x_{n}\right\}$ such that $\left\{x_{n_{j}}\right\}$ converges 
weakly to some $z \in C$ and $z \neq x$. As in the case of $x$, we can also see that $z \in F(T)$. It follows that $\lim _{n \rightarrow \infty}\left\|x_{n}-x\right\|$ and $\lim _{n \rightarrow \infty}\left\|x_{n}-z\right\|$ exist. Since $H$ satisfies the Opial condition, we have

$$
\begin{aligned}
& \lim _{n \rightarrow \infty}\left\|x_{n}-x\right\|=\lim _{k \rightarrow \infty}\left\|x_{n_{k}}-x\right\|<\lim _{k \rightarrow \infty}\left\|x_{n_{k}}-z\right\|=\lim _{n \rightarrow \infty}\left\|x_{n}-z\right\|, \\
& \lim _{n \rightarrow \infty}\left\|x_{n}-z\right\|=\lim _{j \rightarrow \infty}\left\|x_{n_{j}}-z\right\|<\lim _{j \rightarrow \infty}\left\|x_{n_{j}}-x\right\|=\lim _{n \rightarrow \infty}\left\|x_{n}-x\right\|,
\end{aligned}
$$

which is a contradiction. We see $x=z$ and hence $\omega_{w}\left(\left\{x_{n}\right\}\right)$ is a singleton. Thus, $\left\{x_{n}\right\}$ converges weakly to $x$ by Lemma 1.2.

Corollary 2.2. Let $C$ be a nonempty closed convex subset of a Hilbert space $H$ and $T: C \rightarrow C$ a uniformly continuous asymptotically $\boldsymbol{\kappa}$-strict pseudocontractive mapping with sequence $\left\{\gamma_{n}\right\}$ such that $F(T) \neq \emptyset$. Let $\left\{x_{n}\right\}_{n=1}^{\infty}$ be a sequence in C generated by the following Ishikawa iterative process:

$$
\begin{gathered}
x_{1} \in C, \\
y_{n}=\beta_{n} T^{n} x_{n}+\left(1-\beta_{n}\right) x_{n}, \\
x_{n+1}=\alpha_{n} T^{n} y_{n}+\left(1-\alpha_{n}\right) x_{n}, \quad \forall n \geq 1,
\end{gathered}
$$

where $\left\{\alpha_{n}\right\}$ and $\left\{\beta_{n}\right\}$ are sequences in $(0,1)$. Assume that the following restrictions are satisfied:

(i) $\sum_{n=1}^{\infty}\left(\left(1+\gamma_{n}\right)^{2}-1\right)<\infty$,

(ii) $0<a \leq \alpha_{n} \leq \beta_{n} \leq b$ for some $a>0$ and $b \in\left(0,\left(-(1-\kappa)^{2}+\right.\right.$ $\left.\left.\sqrt{(1-\kappa)^{4}+2(\kappa+\sqrt{2-\kappa})^{2}(1-\kappa)^{2}}\right) / 2(\kappa+\sqrt{2-\kappa})^{2}\right)$.

Then the sequence $\left\{x_{n}\right\}$ given by (2.15) converges weakly to an element of $F(T)$.

Next, we modify Ishikawa iterative process to get a strong convergence theorem.

Theorem 2.3. Let $C$ be a nonempty closed convex subset of a Hilbert space $H$ and $T: C \rightarrow C$ a uniformly continuous asymptotically $\kappa$-strict pseudocontractive mapping in the intermediate sense with sequence $\left\{\gamma_{n}\right\}$ such that $F(T) \neq \emptyset$ and bounded. Let $\left\{\alpha_{n}\right\}$ and $\left\{\beta_{n}\right\}$ are sequences in $(0,1)$. Let $\left\{x_{n}\right\}_{n=1}^{\infty}$ be a sequence in $C$ generated by the modified Ishikawa iterative process:

$$
\begin{gathered}
x_{1} \in C, \\
y_{n}=\beta_{n} T^{n} x_{n}+\left(1-\beta_{n}\right) x_{n}, \\
z_{n}=\alpha_{n} T^{n} y_{n}+\left(1-\alpha_{n}\right) x_{n} \\
C_{n}=\left\{z \in C:\left\|z_{n}-z\right\|^{2} \leq\left\|x_{n}-z\right\|^{2}+\theta_{n}-\rho_{n}\left\|x_{n}-T^{n} x_{n}\right\|^{2}\right\}, \\
Q_{n}=\left\{z \in C:\left\langle x_{n}-z, x_{1}-x_{n}\right\rangle \geq 0\right\}, \\
x_{n+1}=P_{C_{n} \cap Q_{n}} x_{1},
\end{gathered}
$$

where $\theta_{n}=\alpha_{n} c_{n} M_{1}+\left(2 \gamma_{n}+\gamma_{n}^{2}\right) \Delta_{n}, M_{1}=\sup _{n \geq 1}\left\{\beta_{n}\left(1+\gamma_{n}\right)+2 \kappa \beta_{n} /(1-\kappa)^{2}+1\right\}, \Delta_{n}=$ $\sup \left\{\left\|x_{n}-z\right\|^{2}: z \in F(T)\right\}<\infty$ and $\rho_{n}=\alpha_{n} \beta_{n}\left[1-2 \beta_{n}-\kappa \gamma_{n}-2 \beta_{n}^{2}((\kappa+\sqrt{2-\kappa}) /(1-\kappa))^{2}\right]$ for each 
$n \geq 1$. Assume that the control sequences $\left\{\alpha_{n}\right\}$ and $\left\{\beta_{n}\right\}$ are chosen such that $0<a \leq \alpha_{n} \leq \beta_{n} \leq b$ for some $a>0$ and $b \in\left(0,\left(-(1-\kappa)^{2}+\sqrt{(1-\kappa)^{4}+2(\kappa+\sqrt{2-\kappa})^{2}(1-\kappa)^{2}}\right) / 2(\kappa+\sqrt{2-\kappa})^{2}\right)$. Then the sequence $\left\{x_{n}\right\}$ given by (2.16) converges strongly to an element of $F(T)$.

Proof. We break the proof into six steps.

Step $1\left(C_{n} \cap Q_{n}\right.$ is closed and convex for each $\left.n \geq 1\right)$. It is obvious that $Q_{n}$ is closed and convex and $C_{n}$ is closed for each $n \geq 1$. Note that the defining inequality in $C_{n}$ is equivalent to the inequality

$$
2\left\langle x_{n}-z_{n}, z\right\rangle \leq\left\|x_{n}\right\|^{2}-\left\|z_{n}\right\|^{2}+\theta_{n}-\rho_{n}\left\|x_{n}-T^{n} x_{n}\right\|^{2},
$$

it is easy to see that $C_{n}$ is convex for each $n \geq 1$. Hence, $C_{n} \cap Q_{n}$ is closed and convex for each $n \geq 1$.

Step $2\left(F(T) \subset C_{n} \cap Q_{n}\right.$ for each $\left.n \geq 1\right)$. Let $p \in F(T)$. Following (2.6), (2.7) and the algorithm (2.16), we have

$$
\begin{aligned}
\left\|z_{n}-p\right\|^{2} \leq & \left(1+\gamma_{n}\right)^{2}\left\|x_{n}-p\right\|^{2} \\
& -\alpha_{n} \beta_{n}\left[\left(1+\gamma_{n}\right)\left(1-\beta_{n}\right)-\kappa \gamma_{n}-2 \kappa \beta_{n}^{2}\left(\frac{\kappa+\sqrt{2-\kappa}}{1-\kappa}\right)^{2}-\kappa \beta_{n}\right] \\
& \times\left\|x_{n}-T^{n} x_{n}\right\|^{2}+\alpha_{n} c_{n} M_{1} \\
\leq & \left(1+\gamma_{n}\right)^{2}\left\|x_{n}-p\right\|^{2}-\alpha_{n} \beta_{n}\left[1-2 \beta_{n}-2 \beta_{n}^{2}\left(\frac{\kappa+\sqrt{2-\kappa}}{1-\kappa}\right)^{2}-\kappa \gamma_{n}\right] \\
& \times\left\|x_{n}-T^{n} x_{n}\right\|^{2}+\alpha_{n} c_{n} M_{1} \\
= & \left\|x_{n}-p\right\|^{2}-\rho_{n}\left\|x_{n}-T^{n} x_{n}\right\|^{2}+\alpha_{n} c_{n} M_{1}+\left(2 \gamma_{n}+\gamma_{n}^{2}\right)\left\|x_{n}-p\right\|^{2} \\
\leq & \left\|x_{n}-p\right\|^{2}-\rho_{n}\left\|x_{n}-T^{n} x_{n}\right\|^{2}+\theta_{n},
\end{aligned}
$$

where $\theta_{n}=\alpha_{n} c_{n} M_{1}+\left(2 \gamma_{n}+\gamma_{n}^{2}\right) \Delta_{n}, M_{1}=\sup _{n \geq 1}\left\{\beta_{n}\left(1+\gamma_{n}\right)+2 \kappa \beta_{n} /(1-\kappa)^{2}+1\right\}, \Delta_{n}=$ $\sup \left\{\left\|x_{n}-z\right\|^{2}: z \in F(T)\right\}<\infty$ and $\rho_{n}=\alpha_{n} \beta_{n}\left[1-2 \beta_{n}-\kappa \gamma_{n}-2 \beta_{n}^{2}((\kappa+\sqrt{2-\kappa}) /(1-\kappa))^{2}\right]$ for each $n \geq 1$. Hence $p \in C_{n}$ for each $n \geq 1$.

Next, we show that $F(T) \subset Q_{n}$ for each $n \geq 1$. We prove this by induction. For $n=1$, we have $F(T) \subset C=Q_{1}$. Assume that $F(T) \subset Q_{n}$ for some $n>1$. Since $x_{n+1}$ is the projection of $x_{1}$ onto $C_{n} \cap Q_{n}$, we have

$$
\left\langle x_{n+1}-z, x_{1}-x_{n+1}\right\rangle \geq 0, \quad \forall z \in C_{n} \cap Q_{n} .
$$


By the induction consumption, we know that $F(T) \subset C_{n} \cap Q_{n}$. In particular, for any $p \in F(T)$ we have

$$
\left\langle x_{n+1}-p, x_{1}-x_{n+1}\right\rangle \geq 0
$$

This implies that $p \in Q_{n+1}$. That is, $F(T) \subset Q_{n+1}$. By the principle of mathematical induction, we get $F(T) \subset Q_{n}$ and hence $F(T) \subset C_{n} \cap Q_{n}$ for all $n \geq 1$. This means that the iteration algorithm (2.16) is well defined.

Step $3\left(\lim _{n \rightarrow \infty}\left\|x_{n}-x_{1}\right\|\right.$ exists and $\left\{x_{n}\right\}$ is bounded). In view of (2.16), we see that $x_{n}=P_{Q_{n}} x_{1}$ and $x_{n+1}=P_{C_{n} \cap Q_{n}} x_{1} \in Q_{n}$. It follows that

$$
\left\|x_{n}-x_{1}\right\| \leq\left\|x_{n+1}-x_{1}\right\|
$$

for each $n \geq 1$. We, therefore, obtain that the sequence $\left\{\left\|x_{n}-x_{1}\right\|\right\}$ is nondecreasing. Noticing that $F(T) \subset Q_{n}$ and $x_{n}=P_{Q_{n}} x_{1}$, we have

$$
\left\|x_{1}-x_{n}\right\| \leq\left\|x_{1}-p\right\|, \quad \forall p \in F(T)
$$

This shows that the sequence $\left\{\left\|x_{n}-x_{1}\right\|\right\}$ is bounded. Therefore, the limit of $\left\{\left\|x_{n}-x_{1}\right\|\right\}$ exists and $\left\{x_{n}\right\}$ is bounded.

Step $4\left(x_{n+1}-x_{n} \rightarrow 0\right)$. Observe that $x_{n}=P_{Q_{n}} x_{1}$ and $x_{n+1} \in Q_{n}$ which imply

$$
\left\langle x_{n+1}-x_{n}, x_{1}-x_{n}\right\rangle \leq 0 \text {. }
$$

Using Lemma 1.4, we obtain

$$
\begin{aligned}
\left\|x_{n+1}-x_{n}\right\|^{2} & =\left\|\left(x_{n+1}-x_{1}\right)-\left(x_{n}-x_{1}\right)\right\|^{2} \\
& =\left\|x_{n+1}-x_{1}\right\|^{2}-\left\|x_{n}-x_{1}\right\|^{2}-2\left\langle x_{n+1}-x_{n}, x_{n}-x_{1}\right\rangle \\
& \leq\left\|x_{n+1}-x_{1}\right\|^{2}-\left\|x_{n}-x_{1}\right\|^{2} .
\end{aligned}
$$

Hence, we obtain that $x_{n+1}-x_{n} \rightarrow 0$ as $n \rightarrow \infty$.

Step $5\left(x_{n}-T x_{n} \rightarrow 0\right.$ as $\left.n \rightarrow \infty\right)$. In view of $x_{n+1} \in C_{n}$, we have

$$
\left\|z_{n}-x_{n+1}\right\|^{2} \leq\left\|x_{n}-x_{n+1}\right\|^{2}+\theta_{n}-\rho_{n}\left\|x_{n}-T^{n} x_{n}\right\|^{2} .
$$

On the other hand, we see that

$$
\begin{aligned}
\left\|z_{n}-x_{n+1}\right\|^{2} & =\left\|z_{n}-x_{n}+x_{n}-x_{n+1}\right\|^{2} \\
& =\left\|z_{n}-x_{n}\right\|^{2}+\left\|x_{n}-x_{n+1}\right\|^{2}+2\left\langle z_{n}-x_{n}, x_{n}-x_{n+1}\right\rangle .
\end{aligned}
$$


Combing (2.25) and (2.26) and noting $z_{n}=\alpha_{n} T^{n} y_{n}+\left(1-\alpha_{n}\right) x_{n}$, we obtain that

$$
\alpha_{n}^{2}\left\|T^{n} y_{n}-x_{n}\right\|^{2}+2\left\langle\alpha_{n}\left(T^{n} y_{n}-x_{n}\right), x_{n}-x_{n+1}\right\rangle \leq \theta_{n}-\rho_{n}\left\|x_{n}-T^{n} x_{n}\right\|^{2} .
$$

From the assumption and (2.7), we see that there exists $n_{0} \in \mathbb{N}$ such that

$$
\begin{aligned}
1-2 \beta_{n}-\kappa \gamma_{n}-2 \beta_{n}^{2}\left(\frac{\kappa+\sqrt{2-\kappa}}{1-\kappa}\right)^{2} & \\
\geq & \frac{1}{2}\left(1-2 b-2 b^{2}\left(\frac{\kappa+\sqrt{2-\kappa}}{1-\kappa}\right)^{2}\right)>0, \quad \forall n \geq n_{0} .
\end{aligned}
$$

For any $n \geq n_{0}$, it follows from the definition of $\rho_{n}$ and (2.27) that

$$
\frac{a^{2}}{2}\left(1-2 b-2 b^{2}\left(\frac{\kappa+\sqrt{2-\kappa}}{1-\kappa}\right)^{2}\right)\left\|x_{n}-T^{n} x_{n}\right\|^{2} \leq \theta_{n}+2 \alpha_{n}\left\|T^{n} y_{n}-x_{n}\right\| \cdot\left\|x_{n}-x_{n+1}\right\|
$$

Noting that $\theta_{n} \rightarrow 0$ as $n \rightarrow \infty$ and Step 4, we obtain that

$$
\lim _{n \rightarrow \infty}\left\|x_{n}-T^{n} x_{n}\right\|=0
$$

It follows from Step 4, (2.30) and Lemma 1.7 that $x_{n}-T x_{n} \rightarrow 0$ as $n \rightarrow \infty$.

Step $6\left(x_{n} \rightarrow x \in F(T)\right.$ as $n \rightarrow \infty$, where $\left.x=P_{F(T)} x_{1}\right)$. Since $H$ is reflexive and $\left\{x_{n}\right\}$ is bounded, we get that $\omega_{w}\left(\left\{x_{n}\right\}\right)$ is nonempty. First, we show that $\omega_{w}\left(\left\{x_{n}\right\}\right)$ is a singleton. Assume that $\left\{x_{n_{i}}\right\}$ is subsequence of $\left\{x_{n}\right\}$ such that $x_{n_{i}} \rightarrow x \in C$. Observe that $T$ is uniformly continuous and $\left\|x_{n}-T x_{n}\right\| \rightarrow 0$ as $n \rightarrow \infty$, for any $m \in \mathbb{N}$ we have $\left\|x_{n}-T^{m} x_{n}\right\| \rightarrow 0$ as $n \rightarrow \infty$. From Lemma 1.8, we see that $x \in \omega_{w}\left(\left\{x_{n}\right\}\right) \subset F(T)$.

Since $x_{n+1}=P_{C_{n} \cap Q_{n}} x_{1}$, we obtain that

$$
\left\|x_{1}-x_{n+1}\right\| \leq\left\|x_{1}-P_{F(T)} x_{1}\right\|
$$

for each $n \geq 1$. Observe that $x_{1}-x_{n_{i}} \rightarrow x_{1}-x$ as $n \rightarrow \infty$. By the weak lower semicontinuity of norm, we have

$$
\left\|x_{1}-P_{F(T)} x_{1}\right\| \leq\left\|x_{1}-x\right\| \leq \liminf _{n \rightarrow \infty}\left\|x_{1}-x_{n_{i}}\right\| \leq \limsup _{n \rightarrow \infty}\left\|x_{1}-x_{n_{i}}\right\| \leq\left\|x_{1}-P_{F(T)} x_{1}\right\| .
$$


This implies that

$$
\begin{gathered}
\left\|x_{1}-P_{F(T)} x_{1}\right\|=\left\|x_{1}-x\right\|, \\
\lim _{n \rightarrow \infty}\left\|x_{1}-x_{n_{i}}\right\|=\left\|x_{1}-P_{F(T)} x_{1}\right\| .
\end{gathered}
$$

Hence $x=P_{F(T)} x_{1}$ by the uniqueness of the nearest point projection of $x_{1}$ onto $F(T)$. Since $\left\{x_{n_{i}}\right\}$ is an arbitrary weakly convergent subsequence, it follows that $\omega_{w}\left(\left\{x_{n}\right\}\right)=\{x\}$ and hence $x_{n} \rightarrow x$. It is easy to see as (2.34) that $\left\|x_{1}-x_{n}\right\| \rightarrow\left\|x_{1}-x\right\|$. Since $H$ has the Kadec-Klee property, we obtain that $x_{1}-x_{n} \rightarrow x_{1}-x$, that is, $x_{n} \rightarrow x=P_{F(T)} x_{1}$ as $n \rightarrow \infty$. This completes the proof.

\section{Acknowledgments}

This research is supported by Fundamental Research Funds for the Central Universities (ZXH2009D021) and supported by the Science Research Foundation Program in Civil Aviation University of China (no. 09CAUC-S05) as well.

\section{References}

[1] K. Goebel and W. A. Kirk, "A fixed point theorem for asymptotically nonexpansive mappings," Proceedings of the American Mathematical Society, vol. 35, pp. 171-174, 1972.

[2] R. E. Bruck, T. Kuczumow, and S. Reich, "Convergence of iterates of asymptotically nonexpansive mappings in Banach spaces with the uniform Opial property," Colloquium Mathematicum, vol. 65, no. 2, pp. 169-179, 1993.

[3] W. A. Kirk, "Fixed point theorems for non-Lipschitzian mappings of asymptotically nonexpansive type," Israel Journal of Mathematics, vol. 17, pp. 339-346, 1974.

[4] L. Qihou, "Convergence theorems of the sequence of iterates for asymptotically demicontractive and hemicontractive mappings," Nonlinear Analysis. Theory, Methods $\mathcal{E}$ Applications, vol. 26, no. 11, pp. 1835-1842, 1996.

[5] Y. X. Tian, S.-S. Chang, J. Huang, X. Wang, and J. K. Kim, "Implicit iteration process for common fixed points of strictly asymptotically pseudocontractive mappings in Banach spaces," Fixed Point Theory and Applications, vol. 2008, Article ID 324575, 12 pages, 2008.

[6] T.-H. Kim and H.-K. Xu, "Convergence of the modified Mann's iteration method for asymptotically strict pseudo-contractions," Nonlinear Analysis. Theory, Methods \& Applications, vol. 68, no. 9, pp. 28282836, 2008.

[7] D. R. Sahu, H.-K. Xu, and J.-C. Yao, "Asymptotically strict pseudocontractive mappings in the intermediate sense," Nonlinear Analysis. Theory, Methods \& Applications, vol. 70, no. 10, pp. 3502-3511, 2009.

[8] M. O. Osilike and S. C. Aniagbosor, "Weak and strong convergence theorems for fixed points of asymptotically nonexpansive mappings," Mathematical and Computer Modelling, vol. 32, no. 10, pp. 1181-1191, 2000.

[9] K.-K. Tan and H.-K. Xu, "The nonlinear ergodic theorem for asymptotically nonexpansive mappings in Banach spaces," Proceedings of the American Mathematical Society, vol. 114, no. 2, pp. 399-404, 1992.

[10] R. P. Agarwal, D. O’Regan, and D. R. Sahu, "Iterative construction of fixed points of nearly asymptotically nonexpansive mappings," Journal of Nonlinear and Convex Analysis, vol. 8, no. 1, pp. 61-79, 2007.

[11] G. Marino and H.-K. Xu, "Weak and strong convergence theorems for strict pseudo-contractions in Hilbert spaces," Journal of Mathematical Analysis and Applications, vol. 329, no. 1, pp. 336-346, 2007. 